\title{
STUDIES ON ACUTE TOXICITY OF HEPTOPLUS IN EXPERIMENTAL RATS
}

\author{
M. SANKAR*, JOHANNA RAJKUMAR \\ Department of Biotechnology, Rajalakshmi Engineering College, Chennai, Tamilnadu, India \\ Email: sankar7950@gmail.com
}

Received: 06 Jul 2016 Revised and Accepted: 09 Sep 2016

\begin{abstract}
Objective: To evaluate acute toxicity of Heptoplus (polyherbal drug) in Sprague-Dawley rats and to identify the active ingredients of the herbal drug

Methods: Heptoplus was subjected to preliminary phytochemical screening and the HPTLC fingerprint profile of herbal drug was documented. OECD guideline 423-Acute toxic class method was followed to evaluate the oral toxicity of Heptoplus in Sprague-Dawley rats. In acute toxicity studies, Group I (control) rats received $0.5 \%$ of carboxymethyl cellouse (Vehicle). Group II rats received $2000 \mathrm{mg} / \mathrm{kg}$ b. w of Heptoplus. The rats were observed on the day of dosing and thereafter for $14 \mathrm{~d}$, for any toxic effect.

Results: Preliminary phytochemical analysis of Heptoplus revealed total phenol, flavonoid, carbohydrate, and tannins as its major constituents. The total phenol and flavonoid content of Heptoplus was found to be $170 \mu \mathrm{g}$ of gallic acid and $162 \mu \mathrm{g}$ of quercetin equivalent. HPTLC analysis proved that phyllanthin is an active compound of Heptoplus. Acute oral toxicity assays showed Heptoplus administration did not result in any treatmentrelated mortality, abnormal clinical signs, and loss of body weight or gross pathological changes in rats. Hence, $\mathrm{LD}_{50}$ value of Heptoplus was found to
\end{abstract} be greater than $2000 \mathrm{mg} / \mathrm{kg} \mathrm{b}$. wt.

Conclusion: Heptoplus contain phyllanthin as an active ingredient. $\mathrm{LD}_{50}$ value of Heptoplus was found to be greater than $2000 \mathrm{mg} / \mathrm{kg} \mathrm{b} . \mathrm{wt}$.

Keywords: Heptoplus, Phyllanthin, Acute toxicity

(C) 2016 The Authors. Published by Innovare Academic Sciences Pvt Ltd. This is an open access article under the CC BY license (http://creativecommons.org/licenses/by/4. 0/] DOI: http://dx.doi.org/10.22159/ijpps.2016v8i11.13934

\section{INTRODUCTION}

In the ancient times, larger use of plants as medicines have been reported which were initially taken in the form of crude drugs such as tinctures, elixirs, poultices, powders, and other herbal formulations. However, use of these herbal products, without scientific origin, is totally useless and unsafe. Furthermore, irrational use of these herbal products may cause serious toxicity to the humans. Unfortunately, many people have an underestimation about the toxicity of natural products, and even they do not realize that these agents could be as toxic as or more than that of synthetic drugs. Toxicology study is one of the important aspects of pharmacology, which deals with the adverse effects of the bioactive substances on living organisms, before use as a drug for ailments. So OECD guideline was established, in order to maintain the safety and efficiency of a new drug. It is extremely important that every new drug has to undergo toxicology studies in animals like mice, rat, guinea pig, dog, rabbit, monkey, etc. under various conditions of the drug [1]. Toxicology studies help us to make a decision, whether a new drug should be adopted for clinical use or not. So OECD 401, 423 and 425 classes emphasize that any new drug before coming to the market has to undergo clinical trial and toxicity studies [2]. The present study is designed to reveal the phytochemical constituents present in the heptoplus and to determine their LD 50 value, by performing acute oral toxicity assay in Sprague-Dawley rats. Heptoplus is a polyherbal drug. Heptoplus contains Phyllanthus amarus (Euphorbiaceae), Eclipta Alba (Asteraceae), Tephrosia purpurea (Fabaceae), Curcuma longa (Zingiberaceae), Picrorhiza kurroa (Plantaginaceae), Withania somnifera (Solanaceae), Pinius succinifera (Pinaceae), Pistacia lentiscus (Anacardiaceae), Orchis mascula (Orchidaceae) and Cycas circinalis (Cycadaceae) as ingredients.

\section{MATERIALS AND METHODS}

\section{Chemicals and reagents}

The chemicals, used in this study were of analytical grade, procured from Ganesh Scientific Suppliers, Chennai, Tamil Nadu.

\section{Heptoplus}

Heptoplus (Tamil Nadu state-licensed drug, Lic. No 616) a polyherbal drug was procured from Care and Cure Herbs Pvt Ltd, Chennai, India, in the form of a capsule. Each capsule has the following composition, which is described in table 1.

Table 1: Composition of heptoplus

\begin{tabular}{llll}
\hline S. No. & Herbal plants & Parts of the plant used & Quantity (mg) \\
\hline 1 & Phyllanthus amarus & Whole plant & 100 \\
2 & Eclipta alba & Leaves & 50 \\
3 & Tephrosia purpurea & Leaves \\
4 & Curcuma longa & Rhizome & 30 \\
5 & Picrorhiza kurroa & Root & 20 \\
6 & Withania somnifera & Root & 100 \\
7 & Pinus succinifera & Amber & 37.50 \\
8 & Pistacia lentiscus & Resinous exudate & 25.00 \\
9 & Orchis mascula & Endosperm & 25.00 \\
10 & Cycas circinalis & Flower Male & 62.50 \\
\hline
\end{tabular}




\section{Phytochemical studies}

\section{Preparation of heptoplus aqueous extract}

A fine powder $(15 \mathrm{~g})$ of heptoplus was taken and added to $90 \mathrm{ml}$ of double distilled water in a dried flask. Then the flask was incubated in a boiling water bath for $1 \mathrm{hr}$ at $100{ }^{\circ} \mathrm{C}$. After the incubation period, the extract was collected using Whatman no. 1 filter paper and evaporated below $50{ }^{\circ} \mathrm{C}$, to obtain the residual mixture. Once the residual mixture was obtained, to that another $50 \mathrm{ml}$ of double distilled water was added and incubated in a water bath for $1 \mathrm{hr}$. Then the extract was collected again using Whatman filter paper no. 1 and evaporated below $40{ }^{\circ} \mathrm{C}$, which was used for further phytochemical analysis. The aqueous extract obtained was then concentrated and the final extract was stored in desiccators for further analysis.

\section{Qualitative analysis of the phytochemical constituents}

Qualitative analysis of the aqueous extract of Heptoplus was performed according to the method of Harborne (1973) [3].

\section{Determination of total phenol content}

The amount of Total phenolic content in the Heptoplus extract was determined by the method of McDonald et, al. (2001) [4].

\section{Estimation of flavonoid content}

The Flavonoid content in the Heptoplus extract was determined by the method of Chang et, al. (2002) [5].

\section{HPTLC profile}

HPTLC analysis for the Heptoplus was performed based on the method of Karthika et, al. (2014) [6].

\section{Animals}

Sprague-Dawley rats, weighing 150 to $200 \mathrm{~g}$ obtained from Sri Ramachandra Medical College, Chennai, India, were used for this study, after the approval from the Institutional Animal Ethics Committee, New Delhi, India, (IACE/XXII/SRU/168/2011). Animals were housed individually in well-ventilated polypropylene cages. A 12 $\mathrm{h}$ light/12-h dark artificial photoperiod, $22^{\circ} \mathrm{C}\left( \pm 3^{\circ}\right)$ room temperature and $50-70 \%$ relative humidity was maintained in the room. Animals had free access to pelleted feed (Nutrilab rodent, Tetragon Chemie Pvt Ltd., India) and reversed osmosis purified water (Rios, USA).

\section{Acute oral toxicity assay}

The acute oral toxicity study was performed according to the OECD test guideline 423-Acute toxic class method-OECD (2001)[7]. Young, healthy adult Sprague-Dawley female rats weighing between 160$180 \mathrm{~g}$ b. wt., were divided into two groups of 3 animals/group. Animals were housed individually in well-ventilated polypropylene cage. A 12-h light/12-h dark artificial photoperiod was maintained. Room temperature $22^{\circ} \mathrm{C}\left( \pm 3^{\circ}\right)$ and relative humidity $50-70 \%$ were maintained in the room. Animals had free access to pelleted feed (Nutrilab rodent, Tetragon Chemie Pvt Ltd., India) and reversed osmosis (Rios, USA) purified water ad libitum. vehicle $(0.5 \%$ carboxymethyl cellulose; CMC) (Group I) or Heptoplus (Group II) was administered once orally via gastric incubation at a dosage of $2000 \mathrm{mg} / \mathrm{Kg}$ b. wt. Lethality and abnormal clinical signs were observed on the day of dosing and thereafter for $14 \mathrm{~d}$. Body weight was recorded before dosing and thereafter once in a week till completion of the experiment. Additional parameters like skin and fur, eyes and mucous membranes, and also respiratory, circulatory, autonomic and central nervous systems, and somatomotor activity and behavior pattern of both control and Heptoplus treated rats were monitored throughout the experimental period. Special attention was given to the observation of parameters like tremors, convulsions, salivation, diarrhea, lethargy, sleep, and coma for the control and Heptoplus treated rats. At the end of the experiment, gross histopathological changes were also observed according to the method of Humason (1979) [8].

\section{Statistical analysis}

All the data are expressed as mean \pm SEM. Statistical significance of data was analyzed by one-way analysis of variance (ANNOVA) followed by Turkey-Kramer multiple comparisons using the Graph pad prism software package for windows (Version 5 ). $\mathrm{P}$ values $<0.05$ are considered as significant.

\section{RESULTS}

Qualitative analysis and quantitative analysis of phytochemical constituents

Preliminary phytochemical screening for the aqueous extract of Heptoplus was carried out to establish the phytochemical constituents present. The inference of phytochemical constituents present in the aqueous extract of Heptoplus is shown in table 2.

Table 2: Qualitative analysis of heptoplus

\begin{tabular}{lll}
\hline Phytochemicals & Observation & Inference \\
\hline Carbohydrates & Purple color & Dark blue color \\
Tannins & Copious formation of foam. & ++ \\
Saponins & Deep yellow color & ++ \\
Flavonoids & Red color & + \\
Quinones & Formation of dark green coloration & ++ \\
Glycosides & Brown ring on the surface & + \\
Cardiac Glycosides & Reddish-brown color & + \\
Terpenoids & Formation of blue color & + \\
Carotenoids & Deep Bluish black color & + \\
Phenols & Purple color was obtained \\
Ninhydrin test & \\
\hline
\end{tabular}

+trace amount and++high content.

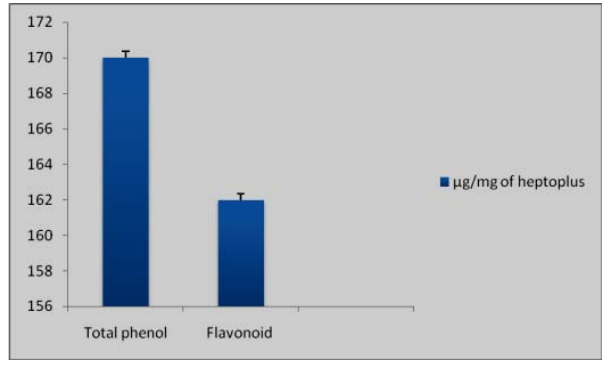

Fig. 1: Total phenol and flavonoid concentration in heptoplus, Values are expressed as mean $\pm \mathrm{SD} \mu \mathrm{g}$ of gallic acid and quercetin equivalent/mg of Heptoplus, where $\mathrm{N}=3$
From this qualitative phytochemical analysis, it is revealed that Heptoplus contains a high amount of flavonoids, carbohydrates, tannins, and phenols. Concurrently saponins, quinones, glycosides, cardiac glycosides, terpenoids, and carotenoids were present in trace amounts. Since phenol and flavonoid, constituents were higher in the aqueous extract of Heptoplus, the total phenol and flavonoids concentration were determined quantitatively; the data obtained are presented in fig. 1

The total phenolic content of the Heptoplus was found to be $170 \mu \mathrm{g}$ gallic acid equivalent/mg of dry weight of extract, whereas flavonoid content was 162 quercetin equivalent/mg dry weight of the extract.

\section{HPTLC analysis of heptoplus}

In the present study, an attempt has been made to establish and to trace one of the active ingredients phyllanthin present in Heptoplus, 
by using HPTLC analysis, although it contains various active ingredients. Table 3 represents the respective peaks and Rf values of Phyllanthin standard and Heptoplus.

Table 3 exhibits the HPTLC fingerprinting of Heptoplus extract and phyllanthin standard. The HPTLC fingerprinting of the Heptoplus extract revealed ten peaks on the application of $8 \mu$ volume at track 7. Concurrently phyllanthin standard exhibited three peaks on the application of $8 \mu \mathrm{l}$ volume at track 4 . Among the 10 peaks of the Heptoplus, the $1^{\text {st }}$ peak is found to be the large one, which occupies $28.46 \%$ in track 7.

Simultaneously among three peaks of the phyllanthin standard, the 1 stpeak found was to the larger one and occupies $84.98 \%$ area in track 4. The corresponding HPTLC chromatogram of both Heptoplus extract and the phyllanthin standard are presented in fig. 2 .

Table 3: The HPTLC relative peaks for heptoplus and the phyllanthin standard

\begin{tabular}{|c|c|c|c|c|c|c|c|c|c|c|}
\hline Track & Peak & Start Rf & Start height & Max Rf & Max Height & Height \% & End Rf & End height & Area & Area \% \\
\hline 4 & 1 & 0.14 & 0.3 & 0.18 & 214.2 & 84.82 & 0.22 & 0.1 & 4091.4 & 84.98 \\
\hline 4 & 2 & 0.24 & 4 & 0.26 & 25.4 & 10.06 & 0.28 & 1 & 501.7 & 10.42 \\
\hline 4 & 3 & 0.3 & 0.2 & 0.32 & 12.9 & 5.12 & 0.33 & 3.9 & 221.6 & 4.6 \\
\hline 7 & 1 & 0.14 & 5.8 & 0.18 & 315.8 & 35.09 & 0.21 & 2.5 & 6976.8 & 28.46 \\
\hline 7 & 2 & 0.22 & 0.3 & 0.26 & 128.2 & 14.24 & 0.29 & 33.6 & 4123.8 & 16.82 \\
\hline 7 & 3 & 0.29 & 34.5 & 0.31 & 74.9 & 8.33 & 0.35 & 24.1 & 2495.7 & 10.18 \\
\hline 7 & 4 & 0.35 & 24.7 & 0.38 & 60.7 & 6.75 & 0.4 & 39 & 1633.1 & 6.66 \\
\hline 7 & 5 & 0.4 & 39.8 & 0.41 & 60.1 & 6.68 & 0.44 & 18.7 & 1373.9 & 5.6 \\
\hline 7 & 6 & 0.44 & 20.3 & 0.48 & 31.6 & 3.51 & 0.49 & 24.6 & 1064.1 & 4.34 \\
\hline 7 & 7 & 0.5 & 25 & 0.55 & 50.1 & 5.56 & 0.55 & 48.1 & 1659.2 & 6.77 \\
\hline 7 & 8 & 0.55 & 48.2 & 0.57 & 79.6 & 8.84 & 0.63 & 0.2 & 2809.5 & 11.46 \\
\hline 7 & 9 & 0.67 & 0.1 & 0.71 & 30.6 & 3.4 & 0.73 & 21.9 & 873.5 & 3.56 \\
\hline 7 & 10 & 0.77 & 18.1 & 0.78 & 24.4 & 2.71 & 0.8 & 2.7 & 483.3 & 1.97 \\
\hline
\end{tabular}

Track-4 represents the relative Rf value for phyllanthin standard. Whereas track-7 represents the relative Rf value for Heptoplus: Rf-Retention factor.

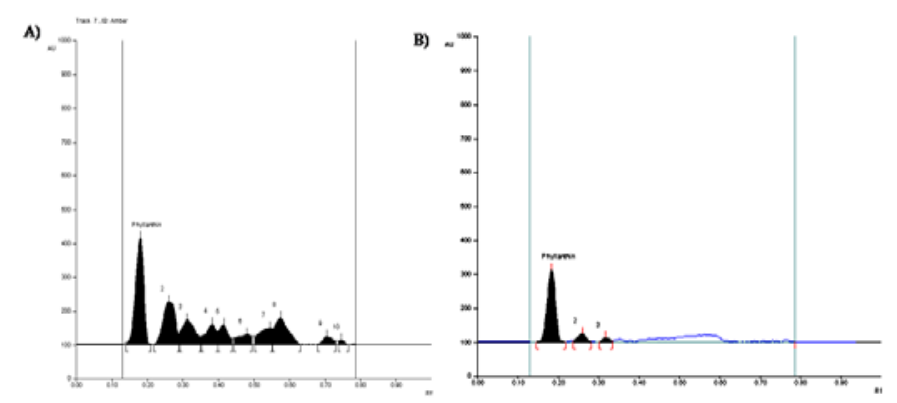

Fig. 2: HPTLC chromatogram of Heptoplus and the Phyllanthin standard, A) Chromatogram of Heptoplus. B) Chromatogram of Phyllanthin standard

From fig. 2, It is crystal clear that the presence of phyllanthin was confirmed in the Heptoplus extract, on comparing the Rf values with phyllanthin standard (Track 4) and Heptoplus extract (track 7). The relative amount of phyllanthin present in the Heptoplus extract was quantitated. The relative amount of phyllanthin present in the Heptoplus was found to be $14.01 \mathrm{ug} / \mathrm{mg}$ of Heptoplus or $1.40 \%$ (w/w). The purity of the Phyllanthin present in the Heptoplus was confirmed by visualizing the chromatogram plate at various spectra; the photo documentation is shown in fig. 3.

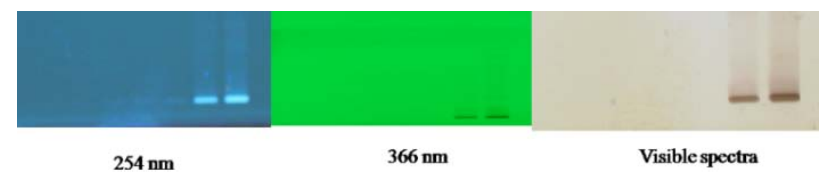

Fig. 3: HPTLC photo documentation of Heptoplus and phyllanthin standard at various wavelengths (8 $\mu \mathrm{l})$

\section{Acute oral toxicity assay of heptoplus on sprague dawley rats}

The acute oral toxicity of Heptoplus was evaluated in accordance with the procedures of a 423-Acute toxic class method. All the observations were systematically recorded with individual records being maintained for each animal. Changes in the wellness parameters and the body weight of the animals were compared with control animals and test group.

\section{Body weight}

The individual body weight of animals was recorded before and after the administration of the drug, as presented in fig. 4.

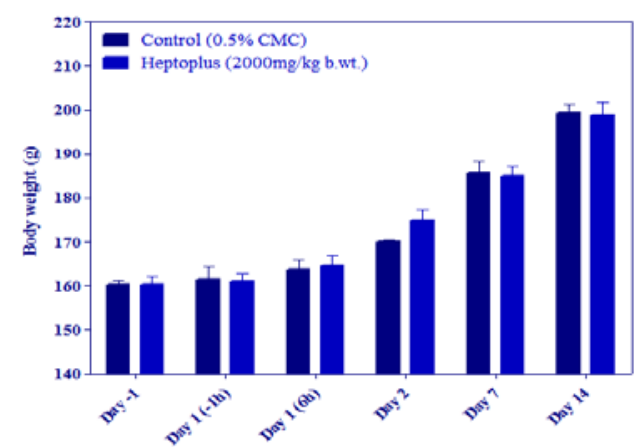

Fig. 4 Effect of heptoplus on body weight of rats, Body weight of experimental rats expressed as mean $\pm S E M$, where $n=3$. No significant deviation of body weight in between control and Heptoplus treated rats. $P$ value $<0.05$ considered as significant. 
There were no significant changes in body weight, between the group I (Control) and group II (Heptoplus treated). All the animals in group I and II, exhibited a normal increase in body weight, during the experimental period.

\section{Wellness parameters}

Wellness parameters of rats, as per the ICH guidelines were observed for a period of $14 \mathrm{~d}$, after dosing and comparing with control rats, which are presented in table 4. During the 14-day period, observation of wellness parameters of skin, fur, and mucous membrane of rats between control and Heptoplus treated groups did not exhibit any significant changes and was found to be completely normal. Special attention was given to neurological parameters such as convulsion, tremor, straub tail reaction, righting, corneal reflexes, akinesia, and catalepsy. Throughout the experimental period, there were no abnormal neurological symptoms observed either in control or in the Heptoplus treated groups. Behaviour response of rats was monitored throughout the experimental period. On observation, it was found that there were no abnormal behavioral symptoms noted either in control or Heptoplus treated group. Apart from this, all the wellness parameters (table 4) were also found to be normal. Hence, this indicates that administration of Heptoplus has a negligible level of toxicity on the growth of the animals.

Table 4: Effect of heptoplus on various wellness parameters

\begin{tabular}{|c|c|c|c|c|c|c|c|c|c|c|c|c|}
\hline \multicolumn{13}{|c|}{ Observation chart of Heptoplus at $2000 \mathrm{mg} / \mathrm{kg}$ of various wellness parameters of rats } \\
\hline \multirow[t]{2}{*}{ Observations/Groups } & \multicolumn{2}{|c|}{$30 \mathrm{~min}$} & \multicolumn{2}{|c|}{$4 \mathrm{~h}$} & \multicolumn{2}{|c|}{$24 \mathrm{~h}$} & \multicolumn{2}{|c|}{$48 \mathrm{~h}$} & \multicolumn{2}{|l|}{$1 \mathrm{w}$} & \multicolumn{2}{|l|}{$2 w$} \\
\hline & I & II & I & II & I & II & I & II & I & II & I & II \\
\hline Lethality & NIL & NIL & NIL & NIL & NIL & NIL & NIL & NIL & NIL & NIL & NIL & NIL \\
\hline Mortality & NIL & NIL & NIL & NIL & NIL & NIL & NIL & NIL & NIL & NIL & NIL & NIL \\
\hline Skin andfur & $\mathrm{N}$ & $\mathrm{N}$ & $\mathrm{N}$ & $\mathrm{N}$ & $\mathrm{N}$ & $\mathrm{N}$ & $\mathrm{N}$ & $\mathrm{N}$ & $\mathrm{N}$ & $\mathrm{N}$ & $\mathrm{N}$ & $\mathrm{N}$ \\
\hline Mucus membrane & $\mathrm{N}$ & $\mathrm{N}$ & $\mathrm{N}$ & $\mathrm{N}$ & $\mathrm{N}$ & $\mathrm{N}$ & $\mathrm{N}$ & $\mathrm{N}$ & $\mathrm{N}$ & $\mathrm{N}$ & $\mathrm{N}$ & $\mathrm{N}$ \\
\hline Excitation & $\mathrm{N}$ & $\mathrm{N}$ & $\mathrm{N}$ & $\mathrm{N}$ & $\mathrm{N}$ & $\mathrm{N}$ & $\mathrm{N}$ & $\mathrm{N}$ & $\mathrm{N}$ & $\mathrm{N}$ & $\mathrm{N}$ & $\mathrm{N}$ \\
\hline Convulsion & NIL & NIL & NIL & NIL & NIL & NIL & NIL & NIL & NIL & NIL & NIL & NIL \\
\hline Tremor & NIL & NIL & NIL & NIL & NIL & NIL & NIL & NIL & NIL & NIL & NIL & NIL \\
\hline Straub tail & NIL & NIL & NIL & NIL & NIL & NIL & NIL & NIL & NIL & NIL & NIL & NIL \\
\hline Jumping & $\mathrm{N}$ & $\mathrm{N}$ & $\mathrm{N}$ & $\mathrm{N}$ & $\mathrm{N}$ & $\mathrm{N}$ & $\mathrm{N}$ & $\mathrm{N}$ & $\mathrm{N}$ & $\mathrm{N}$ & $\mathrm{N}$ & $\mathrm{N}$ \\
\hline Reactivity to touch & $\mathrm{N}$ & $\mathrm{N}$ & $\mathrm{N}$ & $\mathrm{N}$ & $\mathrm{N}$ & $\mathrm{N}$ & $\mathrm{N}$ & $\mathrm{N}$ & $\mathrm{N}$ & $\mathrm{N}$ & $\mathrm{N}$ & $\mathrm{N}$ \\
\hline Fear & $\mathrm{N}$ & $\mathrm{N}$ & $\mathrm{N}$ & $\mathrm{N}$ & $\mathrm{N}$ & $\mathrm{N}$ & $\mathrm{N}$ & $\mathrm{N}$ & $\mathrm{N}$ & $\mathrm{N}$ & $\mathrm{N}$ & $\mathrm{N}$ \\
\hline Muscle tone & $\mathrm{N}$ & $\mathrm{N}$ & $\mathrm{N}$ & $\mathrm{N}$ & $\mathrm{N}$ & $\mathrm{N}$ & $\mathrm{N}$ & $\mathrm{N}$ & $\mathrm{N}$ & $\mathrm{N}$ & $\mathrm{N}$ & $\mathrm{N}$ \\
\hline Aggressiveness & $\mathrm{N}$ & $\mathrm{N}$ & $\mathrm{N}$ & $\mathrm{N}$ & $\mathrm{N}$ & $\mathrm{N}$ & $\mathrm{N}$ & $\mathrm{N}$ & $\mathrm{N}$ & $\mathrm{N}$ & $\mathrm{N}$ & $\mathrm{N}$ \\
\hline Stereotypies chewing) & $\mathrm{N}$ & $\mathrm{N}$ & $\mathrm{N}$ & $\mathrm{N}$ & $\mathrm{N}$ & $\mathrm{N}$ & $\mathrm{N}$ & $\mathrm{N}$ & $\mathrm{N}$ & $\mathrm{N}$ & $\mathrm{N}$ & $\mathrm{N}$ \\
\hline Stereotypies (Head movements) & $\mathrm{N}$ & $\mathrm{N}$ & $\mathrm{N}$ & $\mathrm{N}$ & $\mathrm{N}$ & $\mathrm{N}$ & $\mathrm{N}$ & $\mathrm{N}$ & $\mathrm{N}$ & $\mathrm{N}$ & $\mathrm{N}$ & $\mathrm{N}$ \\
\hline Head twitches & $\mathrm{N}$ & $\mathrm{N}$ & $\mathrm{N}$ & $\mathrm{N}$ & $\mathrm{N}$ & $\mathrm{N}$ & $\mathrm{N}$ & $\mathrm{N}$ & $\mathrm{N}$ & $\mathrm{N}$ & $\mathrm{N}$ & $\mathrm{N}$ \\
\hline Scratching & NIL & NIL & NIL & NIL & NIL & NIL & NIL & NIL & NIL & NIL & NIL & NIL \\
\hline Fore paw treading & NIL & NIL & NIL & NIL & NIL & NIL & NIL & NIL & NIL & NIL & NIL & NIL \\
\hline Catalepsy & NIL & NIL & NIL & NIL & NIL & NIL & NIL & NIL & NIL & NIL & NIL & NIL \\
\hline Akinesia & NIL & NIL & NIL & NIL & NIL & NIL & NIL & NIL & NIL & NIL & NIL & NIL \\
\hline Abnormal gait(rolling) & NIL & NIL & NIL & NIL & NIL & NIL' & NIL' & NIL & NIL & NIL & NIL & NIL \\
\hline Abnormal gait(tiptoe) & NIL & NIL & NIL & NIL & NIL & NIL & NIL & NIL & NIL & NIL & NIL & NIL \\
\hline Motor coordination & $\mathrm{N}$ & $\mathrm{N}$ & $\mathrm{N}$ & $\mathrm{N}$ & $\mathrm{N}$ & $\mathrm{N}$ & $\mathrm{N}$ & $\mathrm{N}$ & $\mathrm{N}$ & $\mathrm{N}$ & $\mathrm{N}$ & $\mathrm{N}$ \\
\hline
\end{tabular}

Table 4: (Continued)

\begin{tabular}{|c|c|c|c|c|c|c|c|c|c|c|c|c|}
\hline \multirow[t]{2}{*}{ Observations/Groups } & \multicolumn{2}{|c|}{$30 \mathrm{~min}$} & \multicolumn{2}{|l|}{$4 \mathrm{~h}$} & \multicolumn{2}{|c|}{$24 \mathrm{~h}$} & \multicolumn{2}{|c|}{$48 \mathrm{~h}$} & \multicolumn{2}{|l|}{$1 \mathrm{w}$} & \multicolumn{2}{|l|}{$2 w$} \\
\hline & I & II & I & II & I & II & I & II & I & II & I & II \\
\hline Loss of balance & NIL & NIL & NIL & NIL & NIL & NIL & NIL & NIL & NIL & NIL & NIL & NIL \\
\hline Loss of traction & NIL & NIL & NIL & NIL & NIL & NIL & NIL & NIL & NIL & NIL & NIL & NIL \\
\hline Loss of grasping & NIL & NIL & NIL & NIL & NIL & NIL & NIL & NIL & NIL & NIL & NIL & NIL \\
\hline Sedation & NIL & NIL & NIL & NIL & NIL & NIL & NIL & NIL & NIL & NIL & NIL & NIL \\
\hline Loss of righting Reflex & NIL & NIL & NIL & NIL & NIL & NIL & NIL & NIL & NIL & NIL & NIL & NIL \\
\hline Loss of corneal reflex & NIL & NIL & NIL & NIL & NIL & NIL & NIL & NIL & NIL & NIL & NIL & NIL \\
\hline Reactivity to touch & $\mathrm{N}$ & $\mathrm{N}$ & $\mathrm{N}$ & $\mathrm{N}$ & $\mathrm{N}$ & $\mathrm{N}$ & $\mathrm{N}$ & $\mathrm{N}$ & $\mathrm{N}$ & $\mathrm{N}$ & $\mathrm{N}$ & $\mathrm{N}$ \\
\hline Writhes & $\mathrm{N}$ & $\mathrm{N}$ & $\mathrm{N}$ & $\mathrm{N}$ & $\mathrm{N}$ & $\mathrm{N}$ & $\mathrm{N}$ & $\mathrm{N}$ & $\mathrm{N}$ & $\mathrm{N}$ & $\mathrm{N}$ & $\mathrm{N}$ \\
\hline Ptosis & NIL & NIL & NIL & NIL & NIL & NIL & NIL & NIL & NIL & NIL & NIL & NIL \\
\hline Exophthalmos & NIL & NIL & NIL & NIL & NIL & NIL & NIL & NIL & NIL & NIL & NIL & NIL \\
\hline Piloerection & NIL & NIL & NIL & NIL & NIL & NIL & NIL & NIL & NIL & NIL & NIL & NIL \\
\hline Defecation & $\mathrm{N}$ & $\mathrm{N}$ & $\mathrm{N}$ & $\mathrm{N}$ & $\mathrm{N}$ & $\mathrm{N}$ & $\mathrm{N}$ & $\mathrm{N}$ & $\mathrm{N}$ & $\mathrm{N}$ & $\mathrm{N}$ & $\mathrm{N}$ \\
\hline Salivation & $\mathrm{N}$ & $\mathrm{N}$ & $\mathrm{N}$ & $\mathrm{N}$ & $\mathrm{N}$ & $\mathrm{N}$ & $\mathrm{N}$ & $\mathrm{N}$ & $\mathrm{N}$ & $\mathrm{N}$ & $\mathrm{N}$ & $\mathrm{N}$ \\
\hline Lacrimation & $\mathrm{N}$ & $\mathrm{N}$ & $\mathrm{N}$ & $\mathrm{N}$ & $\mathrm{N}$ & $\mathrm{N}$ & $\mathrm{N}$ & $\mathrm{N}$ & $\mathrm{N}$ & $\mathrm{N}$ & $\mathrm{N}$ & $\mathrm{N}$ \\
\hline Respiration & $\mathrm{N}$ & $\mathrm{N}$ & $\mathrm{N}$ & $\mathrm{N}$ & $\mathrm{N}$ & $\mathrm{N}$ & $\mathrm{N}$ & $\mathrm{N}$ & $\mathrm{N}$ & $\mathrm{N}$ & $\mathrm{N}$ & $\mathrm{N}$ \\
\hline Others: & $\mathrm{N}$ & $\mathrm{N}$ & $\mathrm{N}$ & $\mathrm{N}$ & $\mathrm{N}$ & $\mathrm{N}$ & $\mathrm{N}$ & $\mathrm{N}$ & $\mathrm{N}$ & $\mathrm{N}$ & $\mathrm{N}$ & $\mathrm{N}$ \\
\hline
\end{tabular}

$\mathrm{N}$ indicates normal. Heptoplus administration did not cause any changes in wellness parameters when compared to group I rats. Group I (Control) and Group II (Heptoplus treated).

\section{Histopathological analysis of major organs}

At the end of the experimental period, rats were subjected to gross pathological examination. On examination of major organs, it was found that there were no lesions or gross pathological changes in any of experimental rats and it was found to be completely normal.
Major organs like liver, kidney, heart, intestine, brain, and lung were subjected to histopathology analysis, the results obtained are represented in a fig. 5 and 6. Histopathological analysis of rat liver, heart, kidney, brain, intestine, and lungs apparently revealed normal architecture, in both the experimental groups. From this analysis, it is revealed that Heptoplus administration is not toxic to the major organs. 

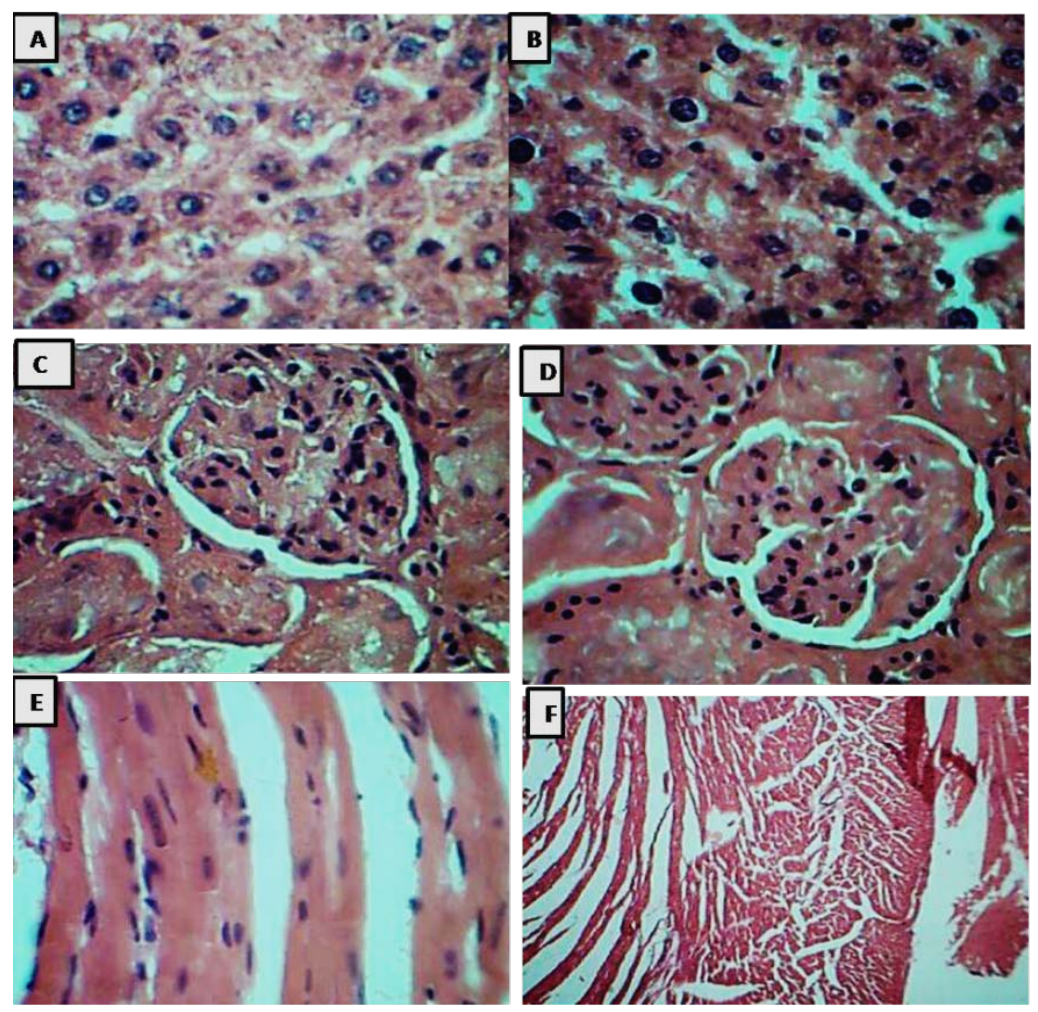

Fig. 5: Histopathological analysis of liver, kidney, and heart treated with Heptoplus in rats (acute oral toxicity assay)

A) Liver section of control rats is exhibiting normal architecture. B) Liver section of rats treated with Heptoplus, exhibiting normal architecture devoid of any lesions or necrosis. C) Kidney sections of control rats are exhibiting normal glomeruli, tubules, and vessels. D) Histological section of a kidney from rats treated with
Heptoplus, exhibiting glomeruli, tubules, and vessels normally. E) Histological section of rat hearts from control group exhibiting normal architecture of myocardium. F) A section of heart treated with Heptoplus, also exhibiting normal architecture of myocardium.
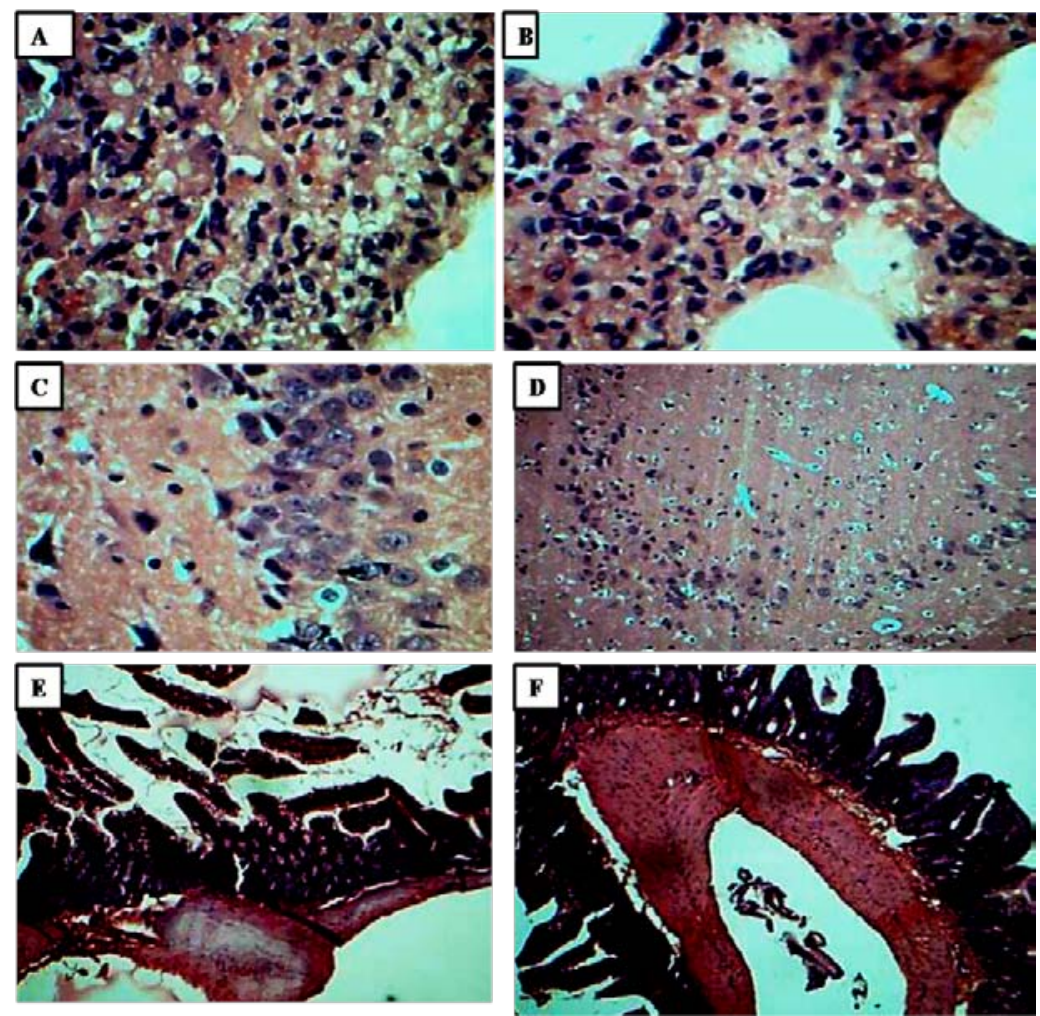

Fig. 7: Histopathological analysis of lungs, brain and intestine treated with heptoplus in rats (acute oral toxicity assay) 
A) Section of Lung's rats (control) exhibiting normal bronchial mucosal epithelium cells. B) Heptoplus exposed lung section of rats displaying normal bronchial epithelial cells. C) A section of rat (Control) brain cortex region is exhibiting normal architecture. D) Cortex section of rat brain treated with Heptoplus, exhibiting normal architecture. E) Intestinal section of control rats with normal architecture. F) Heptoplus exposed an intestinal section of rats exhibiting normal architecture with normal villi.

\section{CONFLICTS OF INTERESTS}

\section{Declared none}

\section{DISCUSSION}

The present study deals with the acute oral toxicity of Heptoplus. International Conference on Harmonization (ICH) recommended and set the guidelines for the test compound, prior to human studies. So any test compound before human studies, it should be evaluated in laboratory animals to determine the effects of test compound on three major vital organ systems, namely the central nervous system (CNS), cardiovascular system, and respiratory system [9]. These assays are performed by the pharmaceutical industry, in order to establish the Good Laboratory Practice (GLP) [10]. In the present study, all the Wellness parameters of rats, as per the ICH guideline were observed for a period of $14 \mathrm{~d}$, after dosing and compared with control rats. When compared to group I rats (control), Group II rats did not exhibit any significant changes or abnormal clinical signs, in the wellness parameters. During the 14-day period, observation of wellness parameters of skin, fur, mucous membrane and behavior patterns of rates between control and Heptoplus treated groups did not exhibit any significant changes and found to be completely normal.

Special attention was given to effects on a central nervous system such as straub tail reaction, convulsion, and tremor. Since alkaloids have an impact on the central nervous system [11]. Straub tail reaction is one of the sensitive biological reactions that occur after the injection of morphine in the rats. During straub tail reaction, the tail of the rat becomes rigid and erected across the back of the animal in an S-shaped curve, which occurs due to the direct stimulation of the spinal cord, nervous system, and also is accompanied by restlessness, excitability, and rigidity in the extension of hind limbs [12]. Moreover, the Straub effect is often used to measure the response to opioids, mediated by $\mu 2$-receptor [13]. Other agonists have also been shown to be able to produce opioids by other mechanisms such as nicotinic and serotoninergic receptor activation [14]. In the present acute toxicity study, neither Heptoplus treated group, nor control group showed straub tail reaction, convulsion, and tremor. It is demonstrated that Heptoplus does not affect the spinal nerves.

Sedatives are the agents that cause decreased activity [15]. Recent studies demonstrated that herbal drugs can exert a sedative and hypnotic effect on the central nervous system [16]. Moreover, the sedative test is performed in rats due to flavonoids, alkaloids, and terpenoids in the plants, which have been reported for their sedative effects [17]. In the present acute toxicity test, it is observed that there were no sedative rats, either in the Heptoplus treated group or in the control animals. This proved that Heptoplus does not induce sedation in experimental rats.

According to Ravikumar et, al. (2013) righting and corneal reflexes are used to assess the neurological responses [18]. In the present acute toxicity study, there was no loss of righting or corneal reflexes in the Heptoplus treated group, when compared with the control group. From this observation, it is revealed that administration of Heptoplus doesn't alter any neurological responses.

The ultimate manifestation of anxiety and fear in the animals is exhibited because of a decrease in motor activity and preference to remain at safer places [19]. Akinesia is a loss of standard motor functions or slowness that causes impaired movement of the muscle, due to the extrapyramidal side effect of the drug [20]. Catalepsy is defined as the failure to correct an externally imposed posture. Catalepsy is a condition, that emphasizes the inactivity, decreased responsiveness to stimuli, and a tendency to maintain an immobile posture and the limbs tend to remain in whatever position they are placed. Catalepsy may be associated with psychotic disorders, nervous system drug toxicity, and other conditions. The catalepsy test is widely performed to evaluate motor effects and extrapyramidal effects of the drug. Writhes is a stretching behavior in response to pain [21]. This abnormal behavior of stretching the muscle is a sign of reduction in motor activity [22]. In the present observation either Heptoplus treated or control rats did not show any abnormal fear, anxiety, catalepsy and abnormal writhes throughout the experimental period. From this, it is clearly indicated that administration of heptoplus does not affect motor neuron activities.

Stereotypy is an abnormal behavior of animals; this behavior may be due to maladaptive, involving self-injury or reduced reproductive success or due to the external environment. Therefore, a stereotype is an altered behavioral response and frequently viewed as a sign of psychological distress in the animals [23]. It is widely accepted that the dopaminergic system in the brain is important in the mediation of drug-induced stereotyped behavior [24]. In the current acute toxicity study, there is no sign of drug-induced abnormal stereotypical behaviors like chewing, head movements, head twitches and scratching observed in the Heptoplus treated group or control group rats. It is clearly demonstrated that administration of Heptoplus does not induce any stereotypical behavior, by altering the dopaminergic system in the brain.

Ptosis is characterized by drooping or falling on the upper or lower eyelid; it occurs only due to the prevalence of nerve damage that controls the eye muscle. It can also be considered as a warning signal for the damage of muscle, nerve, brain, or the eye socket, which is going on. Use of high dose of drugs such as morphine, oxycodone, or hydrocodone can induce ptosis, and it is one of the side effects commonly seen in the abuse of drugs such as heroin [25]. In the current observation, ptosis doesn't occur to the Heptoplus-treated rats, throughout the experimental periods, from this, it is confirmed that administration of Heptoplus will not cause any damage to the nerves and muscle.

Exophthalmos is a condition of a protruding eyeball anteriorly out of the orbit. In the present toxicity study, rats, eyes were monitored daily to examine the presence of any abnormal sign. Throughout experimental periods, Heptoplus treated rats did not show a sign of Exophthalmos. Respiration rate was usually recorded, with related to the cardiac and metabolic function. In the current toxicity analysis, there was no abnormal respiration rate in the Heptoplus treated rats. This indicates that Heptoplus administration is did not affected either cardiac or metabolic functions. Lacrimation and salivation are an autonomic response. In the present toxicity analysis, there was no sign of abnormal lacrimation and salivation in the Heptoplus treated rats, this clearly indicated administration Heptoplus, not altering any autonomic response. Abnormal defecation is a symptom gastrointestinal intestinal poison. In the current toxicity study, abnormal defection was not absorbed either in control or Heptoplus treated rats. This indicates that oral administration of Heptoplus does not lead to gastrointestinal intestinal poisoning condition.

"Since" clinical symptom is one of the major important observations to indicate the toxicity effects on organs in the treated groups. During the $14 \mathrm{~d}$ of a period, acute toxicity evaluation of Heptoplus after the administration did not exhibit any overt signs of distress, and there were no observable symptoms of neither toxicity nor deaths. Instead of that, the entire Heptoplus treated rats gained insignificant weight and displayed no significant changes in the behavior, compared to the control rats. Apart from that, all the wellness parameters (table 4) are also found in normal. Hence, this indicates that administration of Heptoplus has a negligible level of toxicity on the growth of animals.

In addition to this, determination of food intake and water consumption is extremely important for the study of the safety of a product with the therapeutic purpose. Proper intake of nutrients is essential for the physiological status of the animal and accomplished the proper response to the drugs to be tested [26]. In this present study, it was found that there are no adverse changes, neither in the food intake nor the water consumption, between the group, I and group II rats. Which indicate that administration of Heptoplus did 
not induce any appetite suppression or deleterious effects. This indicates Heptoplus administration did not cause any alteration in the physiological status of animals. Based on above oral observation administration of Heptoplus was not caused any treatment-related mortality, abnormal clinical signs; remarkable body weight changes or gross pathological changes observed in any of the experimental animals. Hence the LD 50 value of Heptoplus was found to be greater than $2000 \mathrm{mg} / \mathrm{kg} \mathrm{b.} \mathrm{wt.}$

\section{CONCLUSION}

In the current scenario, it is of utmost important to prove the safety of herbal drugs that are flooding in the market. So an attempt was made in this study to licensed and prove the non-toxicity of Heptoplus a polyherbal drug, which is begin used for the treatment of disease. The acute toxicity showed no adverse effects of the drug on different organs and central nervous system. There was no mortality and the LD 50 value to be greater than $2000 \mathrm{mg} / \mathrm{kg}$ and so totally safe for oral consumption. This study also revealed that one of the active components was phyllanthin responsible for the efficacy of this drug.

\section{CONFLICTS OF INTERESTS}

\section{Declared none}

\section{REFERENCES}

1. Abrar HM, Manjusha S, Mohd YM. An acute oral toxicity study of methanolic extract from Tridex procumbens in sprague dawley's rats as per OECD guidelines 423. Asian J Plant Sci Res 2013;3:16-20.

2. Lalitha P, Shubashini KS, Jayanthi P. Acute toxicity study of extracts of eichhornia crassipes (mart.) solms. Asian J Pharm Clin Res 2012;5:59-61.

3. Harborne JB. Phytochemical methods. 2nd ed. Chapman and Hall publications. London: NewYork; 1988. p. 288.

4. McDonald S, Prenzler PD, Autolovich M, Robards K. Phenolic content and antioxidant activity of olive extracts. Food Chem 2001;73:73-84.

5. Chang CC, Yang MH, Wen HM, Chern JC. Estimation of total flavonoid content in propolis by two complementary colorimetric methods. J Food Drug Anal 2012;10:178-82.

6. Karthika K, Jamuna S, Paulsamy S. TLC and HPTLC fingerprint profiles of different bioactive components from the tuber of Solena amplexicaulis. J Pharmacogn Phytochem 2014;3:198-206.

7. OECD/OCDE 423. OECD guideline for testing of chemicals. Acute oral toxicity-acute toxic class method; 2001.

8. Humason GL. Animal tissue techniques. $4^{\text {th }}$ ed. San Francisco: WH Freeman Co; 1979.

9. Anon. ICHS7A: Safety pharmacology studies for human pharmaceuticals. Federal 421 Register 2001;66:36791-2.

10. Redfern WS, Strang I, Storey S, Heys C, Barnard C, Lawton K, et al. Spectrum of effects detected in the rat functional observational battery following oral administration of non-CNS-targeted compounds. J Pharmacol Toxicol Methods 2005;52:77-82.
11. Muhi-eldeen $\mathrm{Z}$, Al-Shamma KJ, Al-Hussainy TM, Al-Kaissi EN, Al-Daraji AM, Ibrahim H. Acute toxicological studies on the extract of Iraqi peganum harmala in rats. Eur J Sci Res 2008;4:494-500.

12. Bilbey DLJ, Salem JH, Grossman MH. The anatomical basis of the straub phenomenon. Br J Pharmacol 1960;15:540-3.

13. Nath C, Gupta MB, Patnaik GK, Dhawan KN. Morphine-induced straub tail response: mediated by the central $\mu 2$-opioid receptor. Eur J Pharmacol 1994;263:203-5.

14. Zarrindast MR, Alaei-Nia K, Shafizadeh M. On the mechanism of tolerance to morphine-induced straub tail reaction in mice. Pharmacol Biochem Behav 2001;69:419-24.

15. Herrera-Ruiz M, Gutierrez C, Enrique Jimenez-Ferrer J, Tortoriello J, Miron G, Leon I. Central nervous system depressant activity of an ethyl acetate extract from Ipomoea stans roots. J Ethnopharmacol 2007;112:243-7.

16. Huang F, Xiong Y, Xu L, Ma S, Dou C. Sedative and hypnotic activities of the ethanol fraction from Fructus Schisandrae in mice and rats. J Ethnopharmacol 2007;110:471-5.

17. Houghton. The scientific basis for the reputed activity of valerian. J Pharm Pharmacol 1999;51:505-12.

18. Ravikumar M, kishore DV, Jeyanthi Rebecca. Subchronic toxicity analysis of clerodane using rats. Int J Pharm Pharm Sci 2013;5:286-8.

19. Saba Shafeen, Srinath Reddy T, Arafath S, Nagarjuna S, Padmanabha Reddy Y. Evaluation of the antianxiety and antidepressant activity of cassia occidentalis leaves. Asian J Pharm Clin Res 2012;5:47-50.

20. Ittiyavirah SP, Ruby R. Effect of hydro-alcoholic root extract of Plumbago zeylanica $\mathrm{l}$ alone and its combination with aqueous leaf extract of Camellia sinensis on haloperidol-induced parkinsonism in Wistar rats. Ann Neurosci 2014;2:47-50.

21. Derardt R, Journey S, Delevalccee F, Falhout M. Release of prostaglandins $\mathrm{E}$ and $\mathrm{F}$ in an algogenic reaction and its inhibition. Eur J Pharmacol 1980;61:17-24.

22. Tajik H, Tamaddonfard E, Hamzeh-Gooshchi N. The effect of curcumin (active substance of turmeric) on the acetic acidinduced visceral nociception in rats. Pak J Biol Sci 2008;11:312-4.

23. Garner JP, Mason GJ. Evidence for a relationship between cage stereotypies and behavioral disinhibition in laboratory rodents. Behav Brain Res 2002;136:83-92.

24. Sanberg PR, Bunsey MD, Giordano M, Norman AB. The catalepsy test: its ups and Downs. Behav Neurosci 1988;102:748-59.

25. Finsterer J. Ptosis: causes, presentation, and management. Chin J Aesthetic Plast Surg 2003;27:193-204.

26. Iversen PO, Nicolaysen G. Water for life. J Norw Med Assoc 2003;123:3402-5.

\section{How to cite this article}

- M Sankar, Johanna Rajkumar. Studies on the acute toxicity of heptoplus in experimental rats. Int J Pharm Pharm Sci 2016;8(11):124-130. 